\title{
Reward learning as a potential target for pharmacological augmentation of cognitive remediation for schizophrenia: a roadmap for preclinical development
}

\author{
Dean T. Acheson ${ }^{1,2}$, Elizabeth W. Twamley ${ }^{1,3}$ and Jared W. Young ${ }^{1,2 *}$ \\ ${ }^{1}$ Department of Psychiatry, University of California San Diego, La Jolla, San Diego, CA, USA \\ 2 Research Service, San Diego Veteran's Affairs Hospital, San Diego, CA, USA \\ ${ }^{3}$ VA San Diego Healthcare System, Center of Excellence for Stress and Mental Health, San Diego, CA, USA
}

\section{Edited by: \\ Eleanor Dommett, The Open \\ University, UK}

Reviewed by:

Charles H. Large, Autifony

Therapeutics Limited, Italy

Anthony J. Hannan, University of

Melbourne, Australia

*Correspondence:

Jared W. Young, Department of

Psychiatry, University of California

San Diego, 9500 Gilman Drive MC

0804, CTF C214, La Jolla

San Diego, CA 92093-0804, USA

e-mail: jaredyoung@ucsd.edu
Rationale: Impaired cognitive abilities are a key characteristic of schizophrenia. Although currently approved pharmacological treatments have demonstrated efficacy for positive symptoms, to date no pharmacological treatments successfully reverse cognitive dysfunction in these patients. Cognitively-based interventions such as cognitive remediation (CR) and other psychosocial interventions however, may improve some of the cognitive and functional deficits of schizophrenia. Given that these treatments are time-consuming and labor-intensive, maximizing their effectiveness is a priority. Augmenting psychosocial interventions with pharmacological treatments may be a viable strategy for reducing the impact of cognitive deficits in patients with schizophrenia.

Objective: We propose a strategy to develop pharmacological treatments that can enhance the reward-related learning processes underlying successful skill-learning in psychosocial interventions. Specifically, we review clinical and preclinical evidence and paradigms that can be utilized to develop these pharmacological augmentation strategies. Prototypes for this approach include dopamine D1 receptor and $\alpha 7$ nicotinic acetylcholine receptor agonists as attractive targets to specifically enhance reward-related learning during CR.

Conclusion: The approach outlined here could be used broadly to develop pharmacological augmentation strategies across a number of cognitive domains underlying successful psychosocial treatment.

Keywords: schizophrenia, cognitive remediation, augmentation, DRD1, nAChR

\section{INTRODUCTION}

The primary treatments for schizophrenia are antipsychotic medications, which target psychotic symptoms, but leave patients with considerable disability due to negative and cognitive symptoms (Harvey and Keefe, 2001; Carter, 2005; Keefe et al., 2007; Mintz and Kopelowicz, 2007). To date, no drugs have been approved for treating negative symptoms or cognitive dysfunction in schizophrenia (Floresco et al., 2005; Geyer, 2010). Although there has evidence for modest antipsychotic-induced improvement in cognition (Bilder et al., 2002; Weiss et al., 2002; Weiner et al., 2004; Keefe et al., 2007), several investigators and clinicians have questioned the real-world clinical relevance of these effects. For example, antipsychotic-induced improvement of patients' ability to recall a 12 -word list by a tenth of a word, while statistically significant (Keefe et al., 2007), may not be clinically meaningful (Heinrichs, 2007). Some effect sizes may be greater, but certainly no drug-induced normalization of cognition has occurred for patients with schizophrenia. To address this great unmet therapeutic need (Floresco et al., 2005), the United States National Institute of Mental Health sponsored several initiatives. These initiatives include: (1) Measurement and Treatment Research to Improve Cognition in Schizophrenia (MATRICS;
Marder and Fenton, 2004; Marder, 2006); (2) the Treatment Units for Research on Neurocognition in Schizophrenia (TURNS; Buchanan et al., 2007); and (3) Cognitive Neuroscience Treatment to Improve Cognition in Schizophrenia (CNTRICS; Carter and Barch, 2007). The MATRICS group developed a consensus clinical test battery (MATRICS Consensus Cognitive Battery; MCCB) for use in trials of cognitive enhancers considered for Food and Drug Administration approval. TURNS was designed to select and evaluate potential procognitive candidates and CNTRICS is currently developing novel tasks from cognitive neuroscience for use in clinical neuroscience with corresponding animal paradigms. To date, however, there has been limited success in clinical trials of treatments aiming to reverse cognitive deficits in patients with schizophrenia (Javitt et al., 2012; Keefe et al., 2013). A CNTRICS battery may take several years to develop. If testing in rodents occurs first, it may be a decade before a CNTRICS battery will even assess a putative therapeutic drug in humans.

The lack of development of procognitive drugs has impacted investment in the field to the extent that many major pharmaceutical companies are no longer employing researchers in this area, a trend seen in CNS drug-development in general 
(Nutt and Goodwin, 2011). The failure to develop procognitive drugs for schizophrenia could lie in the fact that nearly all attempts have sought a single treatment for a disease likely resulting from multiple neurodevelopmental insults and subsequent compensatory changes (Bigos et al., 2010; Kleinman et al., 2011). With volumetric and/or morphometric abnormalities in $>20$ brain regions (Levitt et al., 2010), developing a single treatment to normalize such widespread disturbances seems unlikely. A problem with this level of complexity requires innovative solutions. In this paper, we briefly review the literature on the cognitive remediation (CR) approach to treatment and propose a roadmap for developing pharmaceuticals acting in synergy with $\mathrm{CR}$ and other psychosocial treatments aimed at improving cognition in schizophrenia.

\section{COGNITIVELY-BASED PSYCHOSOCIAL TREATMENTS}

Partially in response to the limited efficacy of traditional pharmacotherapy on cognitive deficits, multiple approaches to CR have been developed (Wykes et al., 2011). CR is defined as "a behavioral training based intervention that aims to improve cognitive processes (attention, memory, executive function, social cognition, or metacognition) with the goal of durability and generalization" (Wykes et al., 2011). Not meant to replace traditional pharmacotherapy, these approaches attempt to utilize the functional neurocircuitry remaining in patients in order to train them to acquire the capacity, skills, and/or knowledge needed to address a wide range of issues, e.g., cognitive performance, medication adherence, job skills, and community functioning (Swerdlow, 2011; Wykes et al., 2011). Because a variety of techniques exist, these treatments can be individually tailored to focus on deficits specific to a given patient. Such treatments may be a cost-effective adjunct to pharmacotherapy alone (Gutierrez-Recacha et al., 2006).

CR treatments include "restorative" approaches that aim to repair brain functioning and "compensatory" approaches that aim to use strategies to bypass existing deficits (Twamley et al., 2003; Patterson and Leeuwenkamp, 2008; Kern et al., 2009). Restorative treatments typically involve repetitive practice on cognitive tasks in various domains, assuming that such practice will strengthen cognitive performance and generalize to improved functioning in the community. Compensatory approaches attempt to mitigate existing deficits by teaching new skills and cognitive habits (e.g., Twamley et al., 2012). Both approaches use a variety of tools, such as computer-aided tasks, paper-and-pencil tasks, calendars, checklists, and mnemonics, and both involve positive feedback or praise for successful performance of tasks and strategy use. Thus, through positive feedback, participants are encouraged to enhance their skillset, repeat such performances, and apply their skills in real-life situations.

A growing literature demonstrates the efficacy of CR for improving multiple cognitive and functional domains in schizophrenia patients (Twamley et al., 2003; McGurk et al., 2007; Wykes et al., 2011). A recent meta-analysis of 40 CR studies (Wykes et al., 2011) found moderate effects of CR on cognitive performance $(d=0.45)$ and functioning $(d=0.42)$. Integrated Psychological Therapy, combining elements of CR and other psychosocial therapies, has also been proven effective, with metaanalytic support for effects on cognitive performance $(d=0.54)$, negative symptoms $(d=0.41)$, and social functioning $(d=0.41)$ (Roder et al., 2006).

Other psychosocial treatments for schizophrenia share common features with CR, such as skill learning and positive feedback. Cognitive behavioral therapy (Wykes et al., 2008) focuses on challenging maladaptive thoughts and changing behaviors, whereas social skills training (Kurtz and Mueser, 2008) and social cognitive training (Kurtz and Richardson, 2012) focus on improving social skills and functioning. Although we focus on $\mathrm{CR}$ because it targets cognitive functioning most directly, the roadmap for developing pharmacologic augmentations to psychosocial treatments for schizophrenia would apply to other skill-based psychosocial interventions such as these.

As with antipsychotic treatment alone, the success of CR and other psychosocial interventions is limited, with room for improvement remaining. Moreover, psychosocial treatments require considerable clinical resources, as they are typically implemented by highly trained clinicians over months to years, and even so, are not always successful (Kurtz et al., 2007; Dickinson et al., 2010), with mean effect sizes for improvements in the small to medium range. Additionally, these effect sizes have stayed relatively stable across time, despite improving knowledge regarding the nature of cognitive impairment in schizophrenia and treatment delivery technologies (e.g., computer-aided treatments; McGurk et al., 2007). Recently, Swerdlow and colleagues (Swerdlow, 2011; Chou et al., 2012) have called for a focus on identifying pharmacotherapeutics targeting specific components of neurocognition to synergistically augment psychosocial and cognitive treatments such as CR. For instance, utilizing knowledge regarding the neurobiological basis of reinforcement learning or sensory discrimination, pharmacotherapies might facilitate this process within the context of psychosocial therapy. Importantly, using such pharmacotherapies episodically (i.e., treatment given only immediately prior to CR training sessions and discontinued once the course of CR is completed) may eliminate tolerance issues and enable tighter clinical control of medication use. Indeed, a similar strategy is currently being developed in the treatment of anxiety-related disorders, as we discuss below.

\section{A SYNERGISTIC PHARMACO- AND COGNITIVE-INTERVENTION APPROACH: LESSONS FROM EXPOSURE-BASED PSYCHOTHERAPIES}

Exposure-based treatments are effective in treating a wide range of trauma and anxiety-related disorders, including obsessivecompulsive disorder, panic disorder, social phobia, and posttraumatic stress disorder (Deacon and Abramowitz, 2004). As with psychosocial treatment for schizophrenia, however, room for improvement exists. For example, only $50-70 \%$ of panic disorder patients treated with exposure-based cognitive-behavioral therapy achieve an adequate response following the acute phase of therapy (Furukawa et al., 2006).

Recently, neuroscientists have begun identify the neurobiological and molecular processes mediating the extinction of conditioned fear, the mechanism through which exposure-based 
therapies are thought to work (Bentz et al., 2010). N-methyl-Daspartate (NMDA) receptor activity within the basolateral amygdala is an important mediator of fear extinction memory (Davis, 2002). Preclinical animal studies suggested that D-cycloserine (DCS), a partial agonist of the glycine B $_{\mathrm{B}}$ coagonist site of NMDA receptors (Sheinin et al., 2001), enhanced fear extinction when delivered in a phasic dosing pattern prior to extinction training [see Norberg et al. (2008) for a meta-analytic review]. Clinical research has now documented DCS-facilitation of response to exposure therapy for a range of anxiety disorders (Norberg et al., 2008; De Kleine et al., 2012). In clinical practice, DCS is intended to be delivered approximately $1 \mathrm{~h}$ prior to the exposure therapy sessions. DCS is not administered at any other time and is discontinued following the course of exposure therapy. Despite research on DCS enhancement of exposure therapy being in its infancy, clinical research has begun documenting the efficacy of this strategy for a range of anxiety disorders for which exposure is a significant component of psychosocial treatment, including posttraumatic stress disorder, panic disorder, social phobia, obsessivecompulsive disorder, and specific phobia (Norberg et al., 2008; Otto et al., 2010b; De Kleine et al., 2012). In a review of all clinical studies conducted up to 2008, Norberg and colleagues (2008) found an average Cohen's $d$ of 0.60 (moderate effect) for DCS augmentation of exposure therapy relative to placebo. Additional compounds with putative augmentative functions, such as oxytocin, valproic acid, and 7,8-dihydroxyflavone, are currently under investigation (Kuriyama et al., 2011; Andero and Ressler, 2012; Acheson et al., 2013).

Focus on pharmacological-enhanced neuroplasticity in synergy with psychosocial therapies represents a paradigm shift in the treatment of anxiety-related disorders (Krystal, 2007). Rather than an either-or approach where advances in psychosocial therapy and pharmacotherapy are made independent of one another, this strategy provides a model where knowledge regarding the neurobiological mechanisms underlying the effectiveness of psychosocial therapies is used to identify potential drug targets. This approach is distinct from the traditional model of pharmacopsychosocial combination treatment (i.e., SSRI and CBT), where each treatment has been developed independently, with independent efficacy, without targeted mechanistic interactive effects (Otto et al., 2010a). The synergistic model has generated success within anxiety disorders because (1) the type of learning thought to mediate effective psychosocial treatment, fear extinction, had been identified, and (2) the neurobiological underpinnings of this type of learning had been fairly well elucidated, enabling the identification of putative drug targets. The development of pharmacological and psychosocial co-therapies for schizophrenia is likely to require a similar breakdown of the type of learning used in CR as well as the neurobiology underpinning that learning. We hypothesize that successful CR may be partially mediated by reward-related learning (Figure 1), and that this type of learning may be ubiquitous amongst the various available iterations of CR. If true, developing a better understanding of rewardrelated learning in the context of CR would be important for developing pharmacotherapies to augment CR. Below, we present the logic of the importance for reinforcement learning in CR. Moreover, we propose that two major pro-cognitive targets for schizophrenia, the dopamine D1 receptor (DRD1) and the alpha 7 nicotinic acetylcholine receptor (nAChR), may be ideal for augmenting reward-based learning in $\mathrm{CR}$. To reduce patient burden

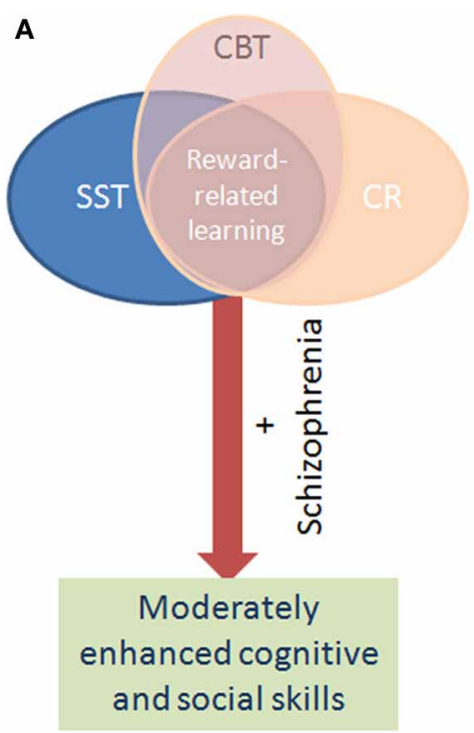

FIGURE 1 | Schematic of the mechanism by which pharmacological augmentation of psychosocial treatment is proposed to work. Psychosocial treatment of cognitive deficits in schizophrenia via cognitive remediation (CR), cognitive behavioral therapy (CBT), and social skills training (SST) rely on positive reinforcement to encourage learning in patients. Through such reinforcement learning, the cognitive performance and hence functional outcome of patients

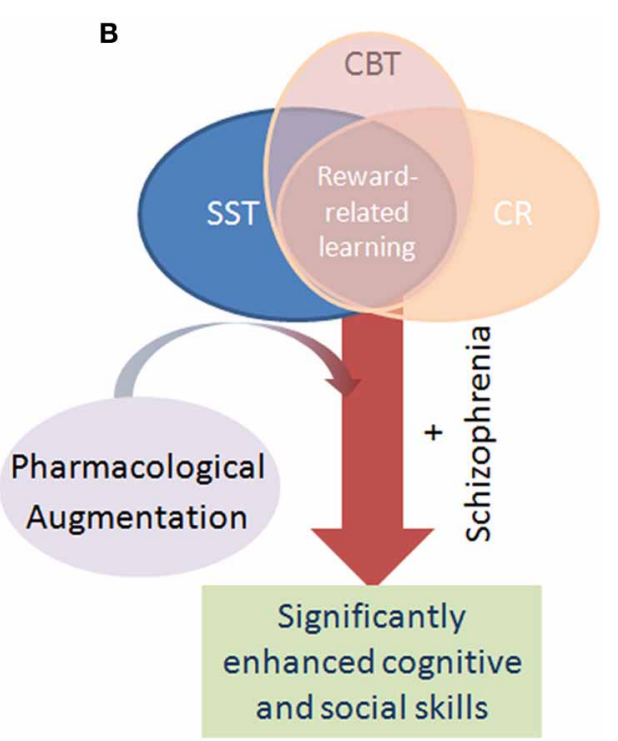

with schizophrenia modestly improve over time (A). Patients with schizophrenia exhibit impaired reward-related learning however, which likely negatively impacts the benefit of these psychosocial interventions. By augmenting these interventions with a pharmacological treatment that enhances reward-related learning, it is theorized that patients will gain maximal benefit from the intervention, resulting in greater improvement than with intervention alone (B) 
and unnecessary medication use and side-effects, phasic dosing of cognitive-enhancing agents could be given only in conjunction with $\mathrm{CR}$, as these drugs are unlikely to produce cognitive benefit when not paired with CR learning activities.

\section{PRECLINICAL RESEARCH FOR PHARMACOLOGICAL AUGMENTATION OF CR REWARD-BASED LEARNING IN CR}

Using animal research in developing pharmaceutical augmentations for CR is hampered by the fact that CR is not conducted in animals. Such was also the case for augmenting exposure-based therapies however, but by identifying the primary mechanism of learning, i.e., fear extinction, it was possible to research this mechanism and identify putative treatments, e.g., DCS. Thus, to aid research for augmenting CR, it is important to identify a sufficiently narrow mechanism-thought to at least partially underlie the effectiveness of psychosocial treatments - which can be pharmacologically targeted. Unfortunately, little is currently known about the mechanism of action underlying CR. Most current research examines cognitive performance or community functioning as primary dependent variables, rather than changes at a molecular level necessary for drug discovery (Twamley et al., 2003; Pfammatter et al., 2006; McGurk et al., 2007; Wykes et al., 2011).

Positive feedback from facilitators, peers, or computers is used in CR to increase desired behaviors as participants learn new skills. Although these are features of almost all CR interventions, two specific examples of the use of positive reinforcement in CR are Silverstein and colleagues' "attention shaping" program (Silverstein et al., 2009) and Vinogradov and colleagues' (Fisher et al., 2010) computer-delivered neuroplasticity-based treatment program to enhance auditory sensory discrimination and verbal learning. In the attention-shaping program, individual attentiveness goals are set for each patient, and the patient is reinforced both verbally and with a token when the goal is met. In the neuroplasticity-based treatment program, correct responses on a verbal memory task are consistently followed by rewarding stimuli to strengthen learning and thereby future verbal memory performance. Both programs have shown promising results on their target cognitive construct, attention and verbal memory respectively (Silverstein et al., 2009; Fisher et al., 2010). Vinogradov and colleagues (2009b) have shown that patients with a heavier anticholinergic burden have a poorer response to $\mathrm{CR}$, and that serum brain derived neurotrophic factor increases after CR (Vinogradov et al., 2009a).

Patients with schizophrenia exhibit deficits in reward-related learning (Waltz et al., 2007, 2011; Weiler et al., 2009), perhaps associated with reduced brain activation following rewardpredicting stimuli in unmedicated patients (Juckel et al., 2006). This deficit probably reflects a fundamental change due to the disease process and not a medication-induced change. Although poor reward-related learning may also reflect lower motivational levels in these patients (Keefe et al., 2011), it is not associated with any negative symptoms and hence unlikely to simply reflect a reduction in reward value (Waltz et al., 2007, 2011; Strauss et al., 2011). Given the positive reinforcement used in CR and other psychosocial treatments, impaired reinforcement learning in patients with schizophrenia may slow treatment progress (Weiler et al., 2009; Strauss et al., 2011).

Pharmacological augmentation of reward-based learning has the potential to improve psychosocial treatments for schizophrenia. In the clinic, pharmaceutical compounds that have been shown to influence the strength and rate of reward learning could be delivered prior to sessions of controlled CR training. Influencing the strength of initial learning might allow for more comprehensive skill acquisition, as well as increased durability of treatment effects over time. Increasing the speed of learning could help to make these treatments more cost-effective and appealing to both providers and service users. For instance, Vinogradov and colleagues (Fisher et al., 2010) reported the most gain from their neuroplasticity-based verbal memory treatment in patients who underwent at least $100 \mathrm{~h}$ of training. Pharmacological augmentation might reduce the training hours required for clinically significant gains, such as has been accomplished with exposurebased psychotherapies for anxiety (Norberg et al., 2008). In order to achieve this goal, there is a clear need for basic preclinical research demonstrating the potential to influence reward-based learning. Preclinical research can also be used to reveal mechanisms underlying reward-based learning as well as testing putative pharmacotherapeutics.

\section{PRECLINICAL STRATEGIES FOR DEVELOPING TREATMENT OPTIONS TO AUGMENT CR}

Just as developing augmentations to exposure-based therapies required an understanding of fear extinction, the use of positive reinforcement in CR supports the need to understand rewardrelated learning mechanisms. It is clear that learning via positive feedback has a different underlying mechanism from learning via punishment or negative reinforcement. To identify mechanisms underlying this learning, tasks with cross-species translational relevance across species should be utilized. Although there are numerous reward-related tasks that require training the animal to perform them, not all have a suitable throughput or crossspecies relevance. For example, training rodents to perform the 5 -choice serial reaction-time task can take more than 2 months (Lustig et al., 2012), during which time repeated treatment effects would be impractical. Moreover, most laboratory tests of learning in healthy humans occur within a single test session. By using tasks with cross-species translational validity for these aspects of learning (Ragland et al., 2009; Young et al., 2009, 2012b), positive treatment findings in normal animals could be confirmed in healthy humans (Ragland et al., 2009) prior to testing in patients.

Thus, the use of positive reinforcement in CR supports the need to focus animal research on reward-related learning mechanisms. Theoretically, pharmacologically-enhanced learning of this type that can be observed both in healthy controls and patients with schizophrenia would be useful because this would suggest a similarly intact neural mechanism that can be engaged in patients (Swerdlow, 2011). Two primary targets identified from MATRICS for the development of procognitive compounds, the DRD1s and $\alpha 7$ nAChRs (Tamminga, 2006; www.matrics.ucla. edu), have been implicated in reward-related learning. These targets represent logical starting points to exemplify developing reward learning-enhancing pharmaceuticals. 


\section{DRD1 AND REWARD-RELATED LEARNING}

Evidence supports dopamine-mediated reward-related learning whereby environmental stimuli and action sequences are encoded via spikes in dopamine levels (Schultz, 2002; Montague et al., 2004; Tobler et al., 2005). Dopamine firing rates may also underlie aversive-related learning, but at lower and shorter durations compared with rewarding stimuli (Joshua et al., 2008; Matsumoto and Hikosaka, 2009; Morris et al., 2010; Glimcher, 2011), supporting the role of dopamine in the reward-prediction-error hypothesis (Glimcher, 2011).

The reward-prediction-error hypothesis provides a putative mechanism underlying Thorndike's Law of Effect. Dopamine fires in response to an unpredicted reward, but once predictable, dopamine firing ceases (Enomoto et al., 2011; Glimcher, 2011). Thus, dopamine strengthens the synaptic connection between reward and action. Importantly, schizophrenia patients exhibit reduced prediction-error signals compared with controls (Gradin et al., 2011). Moreover, striatal dopaminergic neurons are involved in long-term potentiation (LTP), thought to underlie learning (Surmeier et al., 2009), which is also altered in schizophrenia patients (Hasan et al., 2011).

Striatal DRD1s are linked to the direct pathway that stimulates the thalamus and cortex (Gerfen and Engber, 1992; Morris et al., 2010). DRD1 stimulation likely strengthens synaptic connections, promoting LTP (Wolf et al., 2004). Similarly, DRD1 knockout mice exhibit altered LTP and impaired associative learning (Matthies et al., 1997; Granado et al., 2008; Ortiz et al., 2010).

Evidence for DRD1 agonist-induced enhancement of rewardrelated learning is limited, however, in part because few full agonists are available_-most studies utilize partial agonists (e.g., SKF38393; Zhang et al., 2008). Testing whether full DRD1 agonists (e.g., doxanthrine; Przybyla et al., 2009; McCorvy et al., 2012) can improve reward-related learning in animals will be an important next step (Young et al., 2010). Other compounds, such as amphetamine or modafinil, may exert their reward-related effects on behavior in part via a dopamine D1 receptor mechanism (Qu et al., 2008; Young, 2009; Young and Geyer, 2010; Liu et al., 2011; Scoriels et al., 2013). Although there are other diverse mechanisms of actions (Minzenberg and Carter, 2008; Scoriels et al., 2013) of these treatments, it would be useful to determine whether these treatments may be useful to augment CR, and if their pro-learning effects are indeed mediated by the dopamine D1 receptor. Determining treatments with greater dopamine D1 selectivity of effects may be important given the possible role dopamine D2 receptors play in the blockade of learning. Because all antipsychotics are dopamine D2 antagonists, determining the interactive effects of a D1 receptor agonist with D2 receptor blockade will also be important (Young et al., 2012a). The effects of dopamine D2 blockade on rodent cognition alone and in models of schizophrenia have been discussed elsewhere (Hagan and Jones, 2005; Young et al., 2009, 2012c). Moreover, the positive and negative effects of dopamine D2 receptor blockade on cognition in schizophrenia have also been discussed (Harvey and Keefe, 2001; Buchanan et al., 2005; Keefe et al., 2007, 2011). In terms of augmenting CR with a DRD1 agonist or any other treatment, it will be important to identify that any positive treatment will remain so in the presence of chronic antipsychotic treatment (Floresco et al., 2005).

After MATRICS identified the dopamine D1 receptor as a primary target for cognition enhancement in schizophrenia, the NIMH-funded TURNS initiative have assessed the efficacy of the full dopamine D1 agonist dihydrexidine (Mu et al., 2007). Very low doses have had to be used to date however, given orthostatic hypertension, hypotension, and tachycardia that have occurred with intravenous administration (Blanchet et al., 1998), and while it has been tolerated with a subcutaneous dose in patients with schizophrenia it is unclear whether such complications arose (George et al., 2007). Phasic dosing during CR may be an ideal format for administering a treatment with such side-effects (see below).

\section{$\alpha 7$ nAChRs AND REWARD-RELATED LEARNING}

Nicotine (the prototypical ligand of nAChRs) enhances learning in healthy humans, schizophrenia patients, and animals (Levin et al., 1998; Newhouse et al., 2004; Poltavski and Petros, 2006; Barr et al., 2008; Myers et al., 2008; D'Souza and Markou, 2012). Acute mecamylamine (a $\mathrm{nAChR}$ antagonist) impairs learning (Newhouse et al., 1992), while ABT-418 (an $\alpha 4 \beta 2$ nA ChR agonist) improved learning in Alzheimer's disease patients (Potter et al., 1999). Schizophrenia patients exhibit higher smoking rates, which may be a form of self-medication (Kumari and Postma, 2005). Pathological abnormalities of $\alpha 7 \mathrm{nAChRs}$ in schizophrenia patients (e.g., 15q13-15) have been linked to poor sensory gating (Freedman et al., 1997). Lower $\alpha 7 \mathrm{nAChR}$ protein levels are observed in the post-mortem brains of patients with schizophrenia and are associated with cognitive dysfunction (Martin-Ruiz et al., 2003). Moreover, $\alpha 7 \mathrm{nAChR}$ mRNA expression may be regulated by neuregulin-1 genetic variation (Mathew et al., 2007), a genetic risk factor for schizophrenia (Stefansson et al., 2002, 2003; Harrison and Law, 2006; Law et al., 2006). The $\alpha 7$ nAChR modulates numerous mechanisms throughout the brain that are relevant to schizophrenia and its pathophysiology (Bencherif et al., 2012) and may also modulate aspects of cognition (Thomsen et al., 2010). In line with such proposals, $\alpha 7 \mathrm{nAChR}$ knockout mice exhibit impaired reward-related learning across numerous paradigms (Young et al., 2004, 2007a, 2011; Keller et al., 2005; Levin et al., 2009) and impaired LTP (Dziewczapolski et al., 2009), whereas $\alpha 7 \mathrm{nAChR}$ agonists enhance LTP (Lagostena et al., 2008; Kroker et al., 2011). Finally, aversive-motivated learning is intact in $\alpha 7$ nAChR knockout mice (Paylor et al., 1998), suggesting that this receptor specifically contributes to reward-related learning. Thus, $\alpha 7 \mathrm{nAChR}$ abnormalities may impact reward-learning in schizophrenia patients, representing a potential pharmacotherapeutic target, especially as an agonist for this receptor would be less likely than nicotine to be addictive (Martin et al., 2004; Levin and Rezvani, 2006).

Early clinical tests of a partial $\alpha 7 \mathrm{nAChR}$ agonist (DMXBA) were promising with regard to improving cognition in patients with schizophrenia (Olincy et al., 2006), but these effects were not replicated in larger studies (Freedman et al., 2008). When given to rats, daily DMXBA- or nicotine-injections improved learning in aged rats (Levin et al., 1990; Arendash et al., 1995a,b; Taylor et al., 2005). Few studies have characterized the effects of 
such agonists specifically on reward-related learning, however. In a recent review, Hahn and colleagues (2013) discuss the merits of targeting nAChRs as putative add-ons to CR. Primarily, the authors emphasized the ability of nAChR agonists to modestly improve several aspects of cognition, such as attention (Grottick et al., 2003; Young et al., 2004, 2013; Rezvani et al., 2009; Hahn et al., 2011) and working memory (Levin, 2002; Levin et al., 2002; Young et al., 2007b; Rushforth et al., 2010). Thus, they propose that assessing the efficacy of targeted nAChR treatment with CR may provide the best opportunity to enhance cognition and hence functioning in patients with schizophrenia. Recently, Lieberman et al. (2013) demonstrated that the full $\alpha 7 \mathrm{nAChR}$ agonist TC-5619 can modestly improve cognition in patients with schizophrenia. Importantly, this improvement was not blocked by current smoking, an important aspect if such a treatment were used in combination with CR.

$\alpha 7 \mathrm{nAChR}$ agonists should be assessed in combination with CR. Treatment with a cognition-enhancer without structured CR could enhance aspects of learning and habits not conducive to recovery (e.g., paranoid associations). Further, the extant studies on $\alpha 7 \mathrm{nAChR}$ agonists have used a chronic dosing strategy, rather than applying phasic dosing in conjunction with targeted CR. Such phasic dosing may also be more useful in patients that smoke or are ex-smokers, given the high rate of smoking in schizophrenia (Dolan et al., 2004; Dwoskin et al., 2009; D’Souza and Markou, 2012).

\section{METHODS FOR ASSESSING REWARD-RELATED LEARNING AND ITS COMPONENTS IN RODENTS}

There are myriad methods for assessing reward-related learning in rodents. In order to specifically identify treatments that cross the species gap, however, focus should be placed on tasks that can be assessed in rodents and humans (Floresco et al., 2005; Young et al., 2009). Given that exposure-based therapy is essentially similar to what is described as fear extinction in rodents-leading to the development of DCS to augment this mechanism (Norberg et al., 2008) — a reasonable starting point would be to use similar learning paradigms across species.

The CNTRICS initiative identified tasks that can assess reinforcement learning in humans, with putative tasks for testing across species (Ragland et al., 2009). These tasks include the transitive inference paradigm (TIP) and the probabilistic selective task. Given that the task exists in both species, the TIP has evidence for cross-species translational validity (Young et al., 2012b). For example, bilateral hippocampal-lesioned mice exhibit a similar pattern of deficits as do humans with hippocampal lesions (Dusek and Eichenbaum, 1997) and share some similarities to patients with schizophrenia (Titone et al., 2004). The TIP deficits of patients with schizophrenia are also similar to mice with bilateral lesions of the prefrontal cortex, however, where inference deficits are observed but no improvement of extreme value stimuli are observed (Devito et al., 2010). Importantly, TIP deficits are also observed in human subjects with frontal lobe damage, although they can make first order associations readily (Waltz et al., 1999). The probabilistic selective task is also available in both humans and rodents. Although only two studies have been conducted in rats and mice (Bari et al., 2010; Amodeo et al.,
2012), there has been pharmacological consistency between the two rodent species as well as tests in humans (Chamberlain et al., 2006). Importantly, this probabilistic reward task can also differentiate between model-based (learning best strategy) from model-free (repeat responding of rewarded actions) learning (Daw et al., 2011). Such model-based learning is important because there are numerous aspects during CR that must be assimilated into an overall model.

There may of course be other aspects of cognition that contribute to learning from CR, e.g., attention and working memory. As with reinforcement learning, there are tasks that are available to measure these cognitive domains across species. These tasks have been reviewed in detail elsewhere (Young et al., 2009; Dudchenko et al., 2012; Lustig et al., 2012). Importantly, any pharmacological enhancement of any of these tasks in normal rodents could be validated in healthy humans. If the treatment proved modestly efficacious across species, the same treatment could be tested in people with schizophrenia to ensure similar efficacy prior to being tested during CR.

\section{CONCLUSIONS AND FUTURE DIRECTIONS}

As described above, pharmaceutical companies have reduced their investment in pro-cognitive drugs due in part to a lack of positive pro-cognitive effects of treatments for schizophrenia (Nutt and Goodwin, 2011). The approach proposed here provides an avenue by which the pharmaceutical industry can reinitiate their role in developing such treatments. Given that there is another avenue by which treatments - that may have had limited efficacy in the MCCB - could enhance cognition in schizophrenia, clinical trials could be redesigned as described here and elsewhere (Swerdlow, 2011; Chou et al., 2012). Such clinical trials would require phasic treatment only just prior to CR training, as is conducted in DCS treatment combined with behavioral treatment for anxiety disorders. There are several benefits to phasic administration of treatments during CR; (1) Dosing can be controlled by the clinician; (2) Treatments with short half-lives can be used; (3) Side-effects resulting from treatment can be better controlled for (e.g., dihydrexidine); and (4) The treatment is only required for as long as the CR occurs.

This paradigm-shift of combining psychosocial treatment with pharmacotherapies that enhance the underlying neural mechanisms of psychosocial treatments could be essential in enhancing cognition in schizophrenia (Swerdlow, 2011). Designing treatments that work synergistically with CR is essential. Rewardrelated learning appears a reasonable starting point for this strategy. This strategy requires: (1) Confirming the contribution of reward-related learning toward positive CR effects, (2) Elucidating the underlying reward-related learning mechanisms supporting CR; and (3) Identifying treatments that can augment the neurobiological processes supporting these mechanisms (Figure 2). Biomarkers of treatment effects on reward learning, such as LTP (Hasan et al., 2011), or reward-prediction signals (Gradin et al., 2011), can improve the chance of drugdevelopment translating across species (Luck et al., 2011). This strategy may have broad utility across a number of different cognitive domains in addition to reward learning. Further, other disorders characterized by cognitive dysfunction outside of 


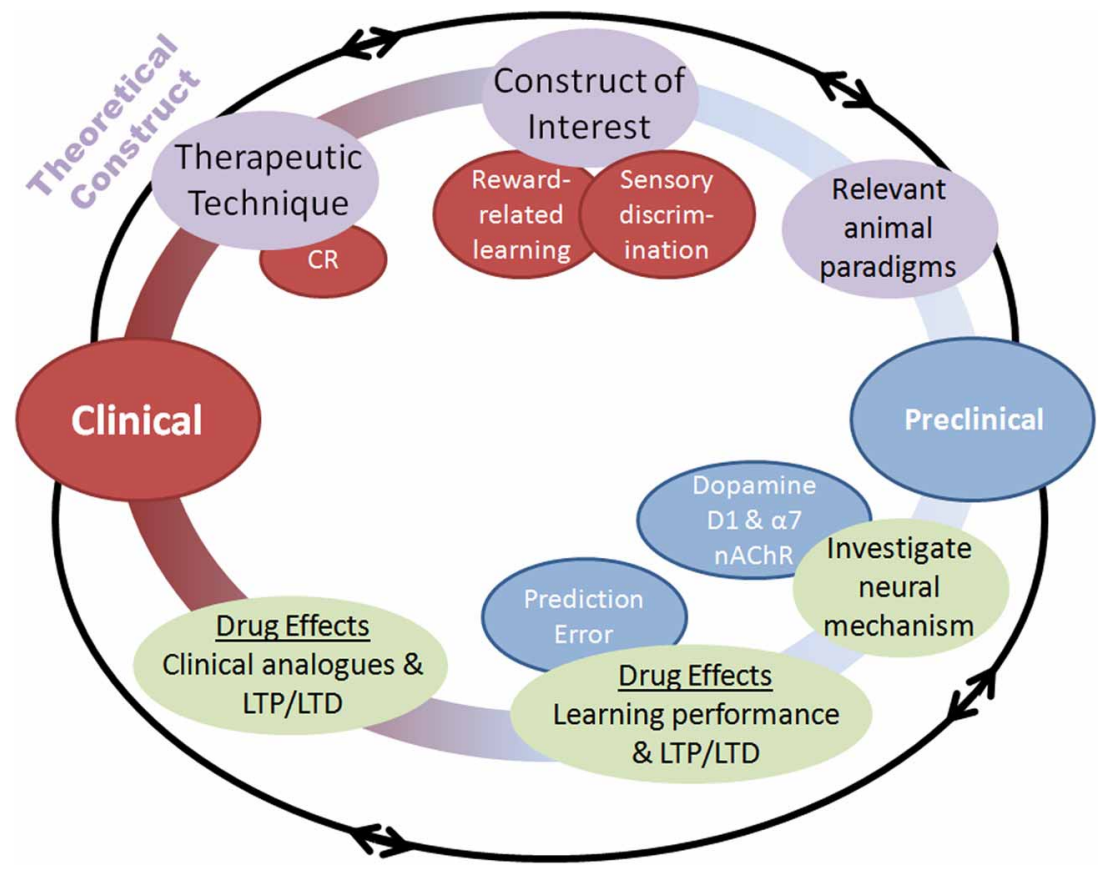

FIGURE 2 | Schematic of the process by which pharmacological augmentations to psychosocial treatments may be developed. Both clinical and preclinical phases are represented, with overlapping and multidirectional processes. Clinical. (1) A therapeutic technique of interest is identified such as cognitive remediation (CR), (2) An underlying cognitive construct to be targeted for augmentation is defined, (3) Animal paradigms with the ability to assay this construct are identified or created. Preclinical. (4) Neural mechanisms underlying the construct of interest are identified, (5) Pharmacological compounds interacting with those neural mechanisms are assessed in animal paradigms for their ability to augment performance, (6) Putative pharmacological augmentations are tested for effectiveness using human clinical analogues in the laboratory before randomized clinical testing. Importantly, this process highlights the bi-directional application of research at each stage, with theoretical constructs leading to testing of hypotheses in animals, which can further refine these constructs. schizophrenia (e.g., bipolar disorder and autism) may also benefit from this approach.

Putative treatments such as DRD1 and $\alpha 7 \mathrm{nAChR}$ agonists may be more effective when used phasically to augment CR as compared to a chronic dosing strategy alone. More general treatments already available, such as modafinil or available nAChR agonists, could be used initially for proof-of-concept. Other targets could be gained from understanding mechanisms underlying neuroplasticity [e.g., LTP, see review by Nicoll and Roche (2013)]. Alternatively, identifying the molecular, structural, and functional correlates of environmental enrichment-dependent plasticity (McOmish and Hannan, 2007) may provide other targets for developing augmentation treatments. Ultimately, combining

\section{REFERENCES}

Acheson, D. T., Feifel, D., de Wilde, S., Mckinney, R., Lohr, J., and Risbrough, V. B. (2013). The effect of intranasal oxytocin treatment on conditioned fear extinction in a healthy human sample. Psychopharmacology (Berl.). doi: 10.1007/s00213-013-3099-4. [Epub ahead of print].

Amodeo, D. A., Jones, J. H., Sweeney, J. A., and Ragozzino, M. E.
(2012). Differences in BTBR $\mathrm{T}+\mathrm{tf} / \mathrm{J}$ and $\mathrm{C} 57 \mathrm{BL} / 6 \mathrm{~J}$ mice on probabilistic reversal learning and stereotyped behaviors. Behav. Brain Res. 227, 64-72. doi: 10.1016/j.bbr.2011.10.032

Andero, R., and Ressler, K. J. (2012). Fear extinction and BDNF: translating animal models of PTSD to the clinic. Genes Brain Behav. 11, 503-512. doi: 10.1111/j.1601183X.2012.00801.X

psychosocial and pharmacological treatments for schizophrenia may be the best opportunity to improve functional outcomes for these patients. We hope that this discussion stimulates research in the field toward that end.

\section{ACKNOWLEDGMENTS}

The authors would like to thank Drs Mark Geyer and Neal Swerdlow for their support.

\section{FUNDING}

This work was supported by Grant support provided by NIMH (R01 MH080150; R21 MH091571; R34 MH93453; P30 $\mathrm{MH} 080002)$ as well as a NARSAD Young Investigator Award.

Arendash, G. W., Sanberg, P. R., and Sengstock, G. J. (1995a). Nicotine enhances the learning and memory of aged rats. Pharmacol. Biochem. Behav. 52, 517-523. doi: 10.1016/0091-3057(95)00119-H

Arendash, G. W., Sengstock, G. J., Sanberg, P. R., and Kem, W. R. (1995b). Improved learning and memory in aged rats with chronic administration of the nicotinic receptor agonist GTS-21. Brain Res. 674, 252-259. doi: 10.1016/0006-8993 (94)01449-R

Bari, A., Theobald, D. E., Caprioli, D., Mar, A. C., Aidoo-Micah, A., Dalley, J. W., et al. (2010). Serotonin modulates sensitivity to reward and negative feedback in a probabilistic reversal learning task in rats. Neuropsychopharmacology 35, 1290-1301. doi: 10.1038/npp. 2009.233 
Barr, R. S., Culhane, M. A., Jubelt, L. E., Mufti, R. S., Dyer, M. A., Weiss, A. P., et al. (2008). The effects of transdermal nicotine on cognition in nonsmokers with schizophrenia and nonpsychiatric controls. Neuropsychopharmacology 33 , 480-490. doi: 10.1038/sj.npp.13 01423

Bencherif, M., Stachowiak, M. K., Kucinski, A. J., and Lippiello, P. M. (2012). Alpha7 nicotinic cholinergic neuromodulation may reconcile multiple neurotransmitter hypotheses of schizophrenia. Med. Hypotheses 78, 594-600. doi: 10.1016/j.mehy.2012. 01.035

Bentz, D., Michael, T., De Quervain, D. J., and Wilhelm, F. H. (2010). Enhancing exposure therapy for anxiety disorders with glucocorticoids: from basic mechanisms of emotional learning to clinical applications. J. Anxiety Disord. 24, 223-230. doi: 10.1016/j.janxdis. 2009.10.011

Bigos, K. L., Mattay, V. S., Callicott, J. H., Straub, R. E., Vakkalanka, R., Kolachana, B., et al. (2010). Genetic variation in CACNA1C affects brain circuitries related to mental illness. Arch. Gen. Psychiatry 67, 939-945. doi: 10.1001/archgenpsychiatry.2010.96

Bilder, R. M., Goldman, R. S., Volavka, J., Czobor, P., Hoptman, M., Sheitman, B., et al. (2002). Neurocognitive effects of clozapine, olanzapine, risperidone, and haloperidol in patients with chronic schizophrenia or schizoaffective disorder. Am. J. Psychiatry 159, 1018-1028. doi: 10.1176/appi.ajp.159.6.1018

Blanchet, P. J., Fang, J., Gillespie, M., Sabounjian, L., Locke, K. W., Gammans, R., et al. (1998). Effects of the full dopamine D1 receptor agonist dihydrexidine in Parkinson's disease. Clin. Neuropharmacol. 21, 339-343.

Buchanan, R. W., Conley, R. R., Dickinson, D., Ball, M. P., Feldman, S., Gold, J. M., et al. (2007). Galantamine for the treatment of cognitive impairments in people with schizophrenia. Am. J. Psychiatry 165, 82-89. doi: 10.1176/appi.ajp. 2007.07050724

Buchanan, R. W., Davis, M., Goff, D., Green, M. F., Keefe, R. S., Leon, A. C., et al. (2005). A summary of the FDA-NIMH-MATRICS workshop on clinical trial design for neurocognitive drugs for schizophrenia. Schizophr. Bull. 31, 5-19. doi: 10.1093/schbul/sbi020
Carter, C. S. (2005). Applying new approaches from cognitive neuroscience to enhance drug development for the treatment of impaired cognition in schizophrenia. Schizophr. Bull. 31, 810-815. doi: 10.1093/schbul/sbi046

Carter, C. S., and Barch, D. M. (2007). Cognitive neurosciencebased approaches to measuring and improving treatment effects on cognition in schizophrenia: the CNTRICS initiative. Schizophr. Bull. 33, 1131-1137. doi: $10.1093 / \mathrm{schbul} / \mathrm{sbm} 081$

Chamberlain, S. R., Muller, U., Blackwell, A. D., Clark, L. Robbins, T. W., and Sahakian, B. J. (2006). Neurochemical modulation of response inhibition and probabilistic learning in humans. Science 311, 861-863. doi: 10.1126/science. 1121218

Chou, H., Twamley, E., and Swerdlow, N. R. (2012). Towards medicationenhancement of cognitive interventions in schizophrenia. Handb. Exp. Pharmacol. 213, 81-111. doi: 10.1007/978-3-64225758-2_4

Davis, M. (2002). Role of NMDA receptors and MAP kinase in the amygdala in extinction of fear: clinical implications for exposure therapy. Eur. J. Neurosci. 16, 395-398. doi: 10.1046/j.14609568.2002.02138.x

Daw, N. D., Gershman, S. J., Seymour, B., Dayan, P., and Dolan, R. J. (2011). Model-based influences on humans' choices and striatal prediction errors. Neuron 69, 1204-1215. doi: 10.1016/j.neuron. 2011.02.027

Deacon, B. J., and Abramowitz, J. S. (2004). Cognitive and behavioral treatments for anxiety disorders: a review of meta-analytic findings. J. Clin. Psychol. 60, 429-441. doi: 10.1002/jclp. 10255

De Kleine, R. A., Hendriks, G. J., Kusters, W. J., Broekman, T. G., and Van Minnen, A. (2012). A randomized placebo-controlled trial of D-cycloserine to enhance exposure therapy for posttraumatic stress disorder. Biol. Psychiatry 71, 962-968. doi: 10.1016/j.biopsych. 2012.02.033

Devito, L. M., Lykken, C., Kanter, B. R., and Eichenbaum, H. (2010). Prefrontal cortex: role in acquisition of overlapping associations and transitive inference. Learn. Mem. 17, 161-167. doi: 10.1101/lm. 1685710

Dickinson, D., Tenhula, W., Morris, S., Brown, C., Peer, J., Spencer, K., et al.
(2010). A randomized, controlled trial of computer-assisted cognitive remediation for schizophrenia. Am. J. Psychiatry 167, 170-180. doi: 10.1176/appi.ajp. 2009.09020264

Dolan, S. L., Sacco, K. A., Termine, A., Seyal, A. A., Dudas, M. M. Vessicchio, J. C., et al. (2004). Neuropsychological deficits are associated with smoking cessation treatment failure in patients with schizophrenia. Schizophr. Res. 70, 263-275. doi: 10.1016/j.schres.2004 01.006

D’Souza, M. S., and Markou, A. (2012). Schizophrenia and tobacco smoking comorbidity: nAChR agonists in the treatment of schizophreniaassociated cognitive deficits. Neuropharmacology 62, 1564-1573. doi: 10.1016/j.neuropharm.2011. 01.044

Dudchenko, P. A., Talpos, J., Young, J., and Baxter, M. G. (2012). Animal models of working memory: a review of tasks that might be used in screening drug treatments for the memory impairments found in schizophrenia. Neurosci. Biobehav. Rev. doi: 10.1016/j.neubiorev. 2012.03.003. [Epub ahead of print].

Dusek, J. A., and Eichenbaum, H. (1997). The hippocampus and memory for orderly stimulus relations. Proc. Natl. Acad. Sci. U.S.A. 94, 7109-7114. doi: 10.1073/pnas. 94.13.7109

Dwoskin, L. P., Pivavarchyk, M. Joyce, B. M., Neugebauer, N. M. Zheng, G., Zhang, Z., et al. (2009). Targeting reward-relevant nicotinic receptors in the discovery of novel pharmacotherapeutic agents to treat tobacco dependence. Nebr. Symp. Motiv. 55, 31-63. doi: 10.1007/978-0-38778748-0 4

Dziewczapolski, G., Glogowski, C. M., Masliah, E., and Heinemann, S. F. (2009). Deletion of the alpha 7 nicotinic acetylcholine receptor gene improves cognitive deficits and synaptic pathology in a mouse model of Alzheimer's disease. J. Neurosci. 29, 8805-8815. doi: 10.1523/ JNEUROSCI.6159-08.2009

Enomoto, K., Matsumoto, N., Nakai, S., Satoh, T., Sato, T. K., Ueda, Y., et al. (2011). Dopamine neurons learn to encode the long-term value of multiple future rewards. Proc. Natl. Acad. Sci. U.S.A. 108, 15462-15467. doi: 10.1073/pnas. 1014457108

Fisher, M., Holland, C., Subramaniam, K., and Vinogradov, S. (2010).
Neuroplasticity-based cognitive training in schizophrenia: an interim report on the effects 6 months later. Schizophr. Bull. 36, 869-879. doi: 10.1093/schbul/ sbn 170

Floresco, S. B., Geyer, M. A., Gold, L. H., and Grace, A. A. (2005). Developing predictive animal models and establishing a preclinical trials network for assessing treatment effects on cognition in schizophrenia. Schizophr. Bull. 31, 888-894. doi: 10.1093/schbul/ sbi041

Freedman, R., Coon, H., MylesWorsley, M., Orr-Urtreger, A., Olincy, A., Davis, A., et al. (1997). Linkage of a neurophysiological deficit in schizophrenia to a chromosome 15 locus. Proc. Natl. Acad. Sci. U.S.A. 94, 587-592. doi: 10.1073/pnas.94.2.587

Freedman, R., Olincy, A., Buchanan, R. W., Harris, J. G., Gold, J. M., Johnson, L., et al. (2008). Initial phase 2 trial of a nicotinic agonist in schizophrenia. Am. J. Psychiatry 165 1040-1047. doi: 10.1176/appi. ajp.2008.07071135

Furukawa, T. A., Watanabe, N., and Churchill, R. (2006). Psychotherapy plus antidepressant for panic disorder with or without agoraphobia: systematic review. $B r$. J. Psychiatry 188, 305-312. doi: 10.1192/bjp.188.4.305

George, M. S., Molnar, C. E., Grenesko, E. L., Anderson, B., Mu, Q. Johnson, K., et al. (2007). A single $20 \mathrm{mg}$ dose of dihydrexidine (DAR0100), a full dopamine D1 agonist, is safe and tolerated in patients with schizophrenia. Schizophr. Res. 93, 42-50. doi: 10.1016/j.schres.2007. 03.011

Gerfen, C. R., and Engber, T. M. (1992). Molecular neuroanatomic mechanisms of Parkinson's disease: a proposed therapeutic approach. Neurol. Clin. 10, 435-449.

Geyer, M. A. (2010). New opportunities in the treatment of cognitive impairments associated with schizophrenia. Curr. Dir. Psychol. Sci. 19, 264-269. doi: 10.1177/0963721410378359

Glimcher, P. W. (2011). Understanding dopamine and reinforcement learning: the dopamine reward prediction error hypothesis. Proc. Natl. Acad. Sci. U.S.A. 108(Suppl. 3), 15647-15654. doi: 10.1073/pnas. 1014269108

Gradin, V. B., Kumar, P., Waiter, G., Ahearn, T., Stickle, C., Milders, M., et al. (2011). Expected value and 
prediction error abnormalities in depression and schizophrenia. Brain 134, 1751-1764. doi: 10.1093/brain/ awr059

Granado, N., Ortiz, O., Suarez, L. M., Martin, E. D., Cena, V., Solis, J. M., et al. (2008). D1 but not D5 dopamine receptors are critical for LTP, spatial learning, and LTP-Induced arc and zif268 expression in the hippocampus. Cereb. Cortex 18, 1-12. doi: 10.1093/ cercor/bhm026

Grottick, A. J., Haman, M., Wyler, R., and Higgins, G. A. (2003). Reversal of a vigilance decrement in the aged rat by subtype-selective nicotinic ligands. Neuropsychopharmacology 28, 880-887. doi: 10.1038/sj.npp. 1300102

Gutierrez-Recacha, P., Chisholm, D., Haro, J. M., Salvador-Carulla, L., and Ayuso-Mateos, J. L. (2006). Cost-effectiveness of different clinical interventions for reducing the burden of schizophrenia in Spain. Acta Psychiatr. Scand. Suppl. 432, 29-38. doi: 10.1111/j.1600-0447. 2006.00917.x

Hagan, J. J., and Jones, D. N. (2005). Predicting drug efficacy for cognitive deficits in schizophrenia. Schizophr. Bull. 31, 830-853. doi: 10.1093/schbul/sbi058

Hahn, B., Gold, J. M., and Buchanan, R. W. (2013). The potential of nicotinic enhancement of cognitive remediation training in schizophrenia. Neuropharmacology 64, 185-190. doi: $\quad$ 10.1016/j.neuropharm.2012. 05.050

Hahn, B., Shoaib, M., and Stolerman, I. P. (2011). Selective nicotinic receptor antagonists: effects on attention and nicotine-induced attentional enhancement. Psychopharmacology (Berl) 217, 75-82. doi: 10.1007/ s00213-011-2258-8

Harrison, P. J., and Law, A. J. (2006). Neuregulin 1 and schizophrenia: genetics, gene expression, and neurobiology. Biol. Psychiatry 60, 132-140. doi: 10.1016/j.biopsych. 2005.11.002

Harvey, P. D., and Keefe, R. S. (2001). Studies of cognitive change in patients with schizophrenia following novel antipsychotic treatment. Am. J. Psychiatry 158, 176-184. doi: 10.1176/appi.ajp.158.2.176

Hasan, A., Nitsche, M. A., Rein, B., Schneider-Axmann, T., Guse, B., Gruber, O., et al. (2011). Dysfunctional longterm potentiation-like plasticity in schizophrenia revealed by transcranial direct current stimulation. Behav. Brain Res. 224, 15-22. doi: 10.1016/j.bbr.2011.05.017
Heinrichs, R. W. (2007). Cognitive improvement in response to antipsychotic drugs: neurocognitive effects of antipsychotic medications in patients with chronic schizophrenia in the CATIE Trial. Arch. Gen. Psychiatry 64, 631-632. doi: 10.1001/archpsyc.64. 6.631

Javitt, D. C., Buchanan, R. W., Keefe, R. S., Kern, R., McMahon, R. P., Green, M. F., et al. (2012). Effect of the neuroprotective peptide davunetide (AL-108) on cognition and functional capacity in schizophrenia. Schizophr. Res. 136, 25-31. doi: 10.1016/j.schres.2011.11.001

Joshua, M., Adler, A., Mitelman, R., Vaadia, E., and Bergman, H. (2008). Midbrain dopaminergic neurons and striatal cholinergic interneurons encode the difference between reward and aversive events at different epochs of probabilistic classical conditioning trials. J. Neurosci. 28, 11673-11684. doi: 10.1523/ JNEUROSCI.3839-08.2008

Juckel, G., Schlagenhauf, F., Koslowski, M., Wustenberg, T., Villringer, A., Knutson, B., et al. (2006). Dysfunction of ventral striatal reward prediction in schizophrenia. Neuroimage 29, 409-416. doi: 10.1016/j.neuroimage.2005.07.051

Keefe, R. S., Bilder, R. M., Davis, S. M., Harvey, P. D., Palmer, B. W., Gold, J. M., et al. (2007). Neurocognitive effects of antipsychotic medications in patients with chronic schizophrenia in the CATIE Trial. Arch. Gen. Psychiatry 64, 633-647. doi: 10.1001/archpsyc.64. 6.633

Keefe, R. S., Buchanan, R. W., Marder, S. R., Schooler, N. R., Dugar, A., Zivkov, M., et al. (2013). Clinical trials of potential cognitiveenhancing drugs in schizophrenia: what have we learned so far? Schizophr. Bull. 39, 417-435. doi: $10.1093 /$ schbul/sbr153

Keefe, R. S., Vinogradov, S., Medalia, A., Silverstein, S. M., Bell, M. D., Dickinson, D., et al. (2011). Report from the working group conference on multisite trial design for cognitive remediation in schizophrenia. Schizophr. Bull. 37, 1057-1065. doi: 10.1093/schbul/ sbq010

Keller, J. J., Keller, A. B., Bowers, B. J., and Wehner, J. M. (2005). Performance of alpha7 nicotinic receptor null mutants is impaired in appetitive learning measured in a signaled nose poke task. Behav. Brain Res. 162, 143-152. doi: 10.1016/j.bbr.2005.03.004
Kern, R. S., Glynn, S. M., Horan, W. P., and Marder, S. R. (2009). Psychosocial treatments to promote functional recovery in schizophrenia. Schizophr. Bull. 35, 347-361. doi: $10.1093 /$ schbul/sbn 177

Kleinman, J. E., Law, A. J., Lipska, B. K. Hyde, T. M., Ellis, J. K., Harrison, P. J., et al. (2011). Genetic neuropathology of schizophrenia: new approaches to an old question and new uses for postmortem human brains. Biol. Psychiatry 69, 140-145. doi: 10.1016/j.biopsych.2010.10.032

Kroker, K. S., Rast, G., and Rosenbrock, H. (2011). Differential effects of subtype-specific nicotinic acetylcholine receptor agonists on early and late hippocampal LTP. Eur. J. Pharmacol. 671, 26-32. doi: 10.1016/j.ejphar.2011.09.167

Krystal, J. H. (2007). Neuroplasticity as a target for the pharmacotherapy of psychiatric disorders: new opportunities for synergy with psychotherapy. Biol. Psychiatry 62, 833-834. doi: 10.1016/j.biopsych.2007.08.017

Kumari, V., and Postma, P. (2005). Nicotine use in schizophrenia: the self medication hypotheses. Neurosci. Biobehav. Rev. 29, 1021-1034. doi: 10.1016/j.neubiorev.2005.02.006

Kuriyama, K., Honma, M., Soshi, T., Fujii, T., and Kim, Y. (2011). Effect of D-cycloserine and valproic acid on the extinction of reinstated fear-conditioned responses and habituation of fear conditioning in healthy humans: a randomized controlled trial. Psychopharmacology (Berl.) 218, 589-597. doi: 10.1007/s00213-011-2353-x

Kurtz, M. M., and Mueser, K. T. (2008). A meta-analysis of controlled research on social skills training for schizophrenia. J. Consult. Clin. Psychol. 76, 491-504. doi: 10.1037/0022-006X.76.3.491

Kurtz, M. M., and Richardson, C. L. (2012). Social cognitive training for schizophrenia: a meta-analytic investigation of controlled research. Schizophr. Bull. 38, 1092-1104. doi: 10.1093/schbul/ sbr036

Kurtz, M. M., Seltzer, J. C., Shagan, D. S., Thime, W. R., and Wexler, B. E. (2007). Computer-assisted cognitive remediation in schizophrenia: what is the active ingredient? Schizophr. Res. 89, 251-260. doi: 10.1016/j.schres.2006.09.001

Lagostena, L., Trocme-Thibierge, C., Morain, P., and Cherubini, E. (2008). The partial alpha7 nicotine acetylcholine receptor agonist S 24795 enhances longterm potentiation at CA3-CA1 synapses in the adult mouse hippocampus. Neuropharmacology 54, 676-685. doi: 10.1016/j.neuropharm.2007.11.016 Law, A. J., Lipska, B. K., Weickert, C. S., Hyde, T. M., Straub, R. E., Hashimoto, R., et al. (2006). Neuregulin 1 transcripts are differentially expressed in schizophrenia and regulated by 5' SNPs associated with the disease. Proc. Natl. Acad. Sci. U.S.A. 103, 6747-6752. doi: 10.1073/pnas.0602002103

Levin, E. D. (2002). Nicotinic receptor subtypes and cognitive function. J. Neurobiol. 53, 633-640. doi: 10.1002/neu.10151

Levin, E. D., Bradley, A., Addy, N., and Sigurani, N. (2002). Hippocampal alpha 7 and alpha 4 beta 2 nicotinic receptors and working memory. Neuroscience 109, 757-765. doi: 10.1016/S03064522(01)00538-3

Levin, E. D., Conners, C. K., Silva, D., Hinton, S. C., Meck, W. H., March, J., et al. (1998). Transdermal nicotine effects on attention. Psychopharmacology (Berl.) 140, 135-141. doi: $10.1007 / \mathrm{s} 002130050750$

Levin, E. D., Lee, C., Rose, J. E., Reyes, A., Ellison, G., Jarvik, M. et al. (1990). Chronic nicotine and withdrawal effects on radialarm maze performance in rats. Behav. Neural Biol. 53, 269-276. doi: 10.1016/0163-1047(90)90509-5

Levin, E. D., Petro, A., Rezvani, A. H., Pollard, N., Christopher, N. C., Strauss, M., et al. (2009). Nicotinic alpha7- or beta2-containing receptor knockout: effects on radial-arm maze learning and long-term nicotine consumption in mice. Behav. Brain Res. 196, 207-213. doi: 10.1016/j.bbr.2008.08.048

Levin, E. D., and Rezvani, A. H. (2006). Nicotinic-antipsychotic drug interactions and cognitive function. EXS 98, 185-205. doi: 10.1007/978-37643-7772-4_10

Levitt, J. J., Bobrow, L., Lucia, D., and Srinivasan, P. (2010). A selective review of volumetric and morphometric imaging in schizophrenia. Curr. Top. Behav. Neurosci. 4, 243-281. doi: 10.1007/7854_2010_53

Lieberman, J. A., Dunbar, G., Segreti, A. C., Girgis, R. R., Seoane, F., Beaver, J. S., et al. (2013). A Randomized exploratory trial of an alpha-7 nicotinic receptor agonist (TC-5619) for cognitive enhancement in schizophrenia. Neuropsychopharmacology 38, 968-975. doi: 10.1038/npp. 2012.259 
Liu, Y., Young, K. A., Curtis, J. T., Aragona, B. J., and Wang, Z. (2011). Social bonding decreases the rewarding properties of amphetamine through a dopamine D1 receptor-mediated mechanism. J. Neurosci. 31, 7960-7966. doi: 10.1523/JNEUROSCI.1006-11.2011

Luck, S. J., Ford, J. M., Sarter, M., and Lustig, C. (2011). CNTRICS final biomarker selection: control of attention. Schizophr. Bull. 38, 53-61. doi: 10.1093/schbul/sbr065

Lustig, C., Kozak, R., Sarter, M., Young, J. W., and Robbins, T. W. (2012). CNTRICS final animal model task selection: control of attention. Neurosci. Biobehav. Rev. doi: 10.1016/j.neubiorev.2012. 05.009. [Epub ahead of print].

Marder, S. R. (2006). Drug initiatives to improve cognitive function. J. Clin. Psychiatry 67(Suppl. 9), 31-35. discussion: 36-42. doi: 10.4088/JCP.0706e03

Marder, S. R., and Fenton, W. (2004). Measurement and Treatment Research to Improve Cognition in Schizophrenia: NIMH MATRICS initiative to support the development of agents for improving cognition in schizophrenia. Schizophr. Res. 72, 5-9. doi: 10.1016/j.schres.2004.09.010

Martin, L. F., Kem, W. R., and Freedman, R. (2004). Alpha-7 nicotinic receptor agonists: potential new candidates for the treatment of schizophrenia. Psychopharmacology (Berl.) 174, 54-64. doi: 10.1007/s00213-003-1750-1

Martin-Ruiz, C. M., Haroutunian, V. H., Long, P., Young, A. H., Davis, K. L., Perry, E. K., et al. (2003). Dementia rating and nicotinic receptor expression in the prefrontal cortex in schizophrenia. Biol. Psychiatry 54, 1222-1233. doi: 10.1016/S0006-3223(03)00348-2

Mathew, S. V., Law, A. J., Lipska, B. K., Davila-Garcia, M. I., Zamora, E. D., Mitkus, S. N., et al. (2007). Alpha7 nicotinic acetylcholine receptor mRNA expression and binding in postmortem human brain are associated with genetic variation in neuregulin 1. Hum. Mol. Genet. 16, 2921-2932. doi: $10.1093 / \mathrm{hmg} / \mathrm{ddm} 253$

Matsumoto, M., and Hikosaka, O. (2009). Representation of negative motivational value in the primate lateral habenula. Nat. Neurosci. 12, 77-84. doi: 10.1038/nn.2233

Matthies, H., Becker, A., Schroeder, H., Kraus, J., Hollt, V., and Krug, M. (1997). Dopamine D1-deficient mutant mice do not express the late phase of hippocampal long-term potentiation. Neuroreport 8, 3533-3535. doi: 10.1097/00001756-19971110000023

McCorvy, J. D., Watts, V. J., and Nichols, D. E. (2012). Comparison of the $\mathrm{D}(1)$ dopamine full agonists, dihydrexidine and doxanthrine, in the 6-OHDA rat model of Parkinson's disease. Psychopharmacology (Berl.) 222, 81-87. doi: 10.1007/s00213-0112625-5

McGurk, S. R., Twamley, E. W., Sitzer, D. I., McHugo, G. J., and Mueser, K. T. (2007). A meta-analysis of cognitive remediation in schizophrenia. Am. J. Psychiatry 164, 1791-1802. doi: 10.1176/appi.ajp.2007.07060906

McOmish, C. E., and Hannan, A. J. (2007). Enviromimetics: exploring gene environment interactions to identify therapeutic targets for brain disorders. Expert Opin. Ther. Targets 11, 899-913. doi: 10.1517/14728222.11.7.899

Mintz, J., and Kopelowicz, A. (2007). CUtLASS confirms CATIE. Arch. Gen. Psychiatry 64, 978; author reply: 979-980. doi: 10.1001/archpsyc.64.8.978-a

Minzenberg, M. J., and Carter, C. S. (2008). Modafinil: a review of neurochemical actions and effects on cognition. Neuropsychopharmacology 33, 1477-1502. doi: 10.1038/sj.npp. 1301534

Montague, P. R., McClure, S. M., Baldwin, P. R., Phillips, P. E., Budygin, E. A., Stuber, G. D., et al. (2004). Dynamic gain control of dopamine delivery in freely moving animals. J. Neurosci. 24, 1754-1759. doi: 10.1523/JNEUROSCI.4279-03.2004

Morris, G., Schmidt, R., and Bergman, H. (2010). Striatal action-learning based on dopamine concentration. Exp. Brain Res. 200, 307-317. doi: 10.1007/s00221-009-2060-6

$\mathrm{Mu}$, Q., Johnson, K., Morgan, P. S., Grenesko, E. L., Molnar, C. E., Anderson, B., et al. (2007). A single $20 \mathrm{mg}$ dose of the full D1 dopamine agonist dihydrexidine (DAR-0100) increases prefrontal perfusion in schizophrenia. Schizophr. Res. 94, 332-341. doi: 10.1016/j.schres.2007.03.033

Myers, C. S., Taylor, R. C., Moolchan, E. T., and Heishman, S. J. (2008). Dose-related enhancement of mood and cognition in smokers administered nicotine nasal spray. Neuropsychopharmacology 33, 588-598. doi: 10.1038/sj.npp. 1301425
Newhouse, P., Singh, A., and Potter, A. (2004). Nicotine and nicotinic receptor involvement in neuropsychiatric disorders. Curr. Top. Med. Chem. 4, 267-282. doi: 10.2174/1568026043451401

Newhouse, P. A., Potter, A., Corwin, J., and Lenox, R. (1992). Acute nicotinic blockade produces cognitive impairment in normal humans. Psychopharmacology (Berl.) 108, 480-484. doi: 10.1007/ BF02247425

Nicoll, R. A., and Roche, K. W. (2013). Long-term potentiation: peeling the onion. Neuropharmacology. doi: 10.1016/j.neuropharm.2013.02.010. [Epub ahead of print].

Norberg, M. M., Krystal, J. H., and Tolin, D. F. (2008). A meta-analysis of D-cycloserine and the facilitation of fear extinction and exposure therapy. Biol. Psychiatry 63, 1118-1126. doi: 10.1016/j.biopsych. 2008.01.012

Nutt, D., and Goodwin, G. (2011). ECNP Summit on the future of CNS drug research in Europe 2011: report prepared for ECNP by David Nutt and Guy Goodwin. Eur. Neuropsychopharmacol. 21, 495-499. doi: 10.1016/j.euroneuro. 2011.05.004

Olincy, A., Harris, J. G., Johnson, L. L. Pender, V., Kongs, S., Allensworth, D., et al. (2006). Proof-of-concept trial of an alpha7 nicotinic agonist in schizophrenia. Arch. Gen. Psychiatry 63, 630-638. doi: 10.1001/archpsyc.63.6.630

Ortiz, O., Delgado-Garcia, J. M., Espadas, I., Bahi, A., Trullas, R., Dreyer, J. L., et al. (2010). Associative learning and CA3-CA1 synaptic plasticity are impaired in D1R null, Drdla-/- mice and in hippocampal siRNA silenced Drdla mice. J. Neurosci. 30, 12288-12300. doi: 10.1523/JNEUROSCI.2655-10.2010

Otto, M. W., McHugh, R. K., and Kantak, K. M. (2010a). Combined pharmacotherapy and cognitivebehavioral therapy for axiety disorders: medication effects, glucocorticoids, and attenuated treatment outcomes. Clin. Psychol. Sci. Prac. 17, 91-103. doi: 10.1111/j.1468-2850.2010.01198.x

Otto, M. W., Tolin, D. F., Simon, N. M., Pearlson, G. D., Basden, S., Meunier, S. A., et al. (2010b). Efficacy of d-cycloserine for enhancing response to cognitivebehavior therapy for panic disorder. Biol. Psychiatry 67, 365-370. doi: 10.1016/j.biopsych.2009.07.036

Patterson, T. L., and Leeuwenkamp, O. R. (2008). Adjunctive psychosocial therapies for the treatment of schizophrenia. Schizophr. Res. 100 108-119. doi: 10.1016/j.schres.2007. 12.468

Paylor, R., Nguyen, M., Crawley, J. N., Patrick, J., Beaudet, A., and OrrUrtreger, A. (1998). Alpha7 nicotinic receptor subunits are not necessary for hippocampal-dependent learning or sensorimotor gating: a behavioral characterization of Acra7-deficient mice. Learn. Mem. 5, 302-316. doi: 10.1101/lm.5.4.302

Pfammatter, M., Junghan, U. M., and Brenner, H. D. (2006). Efficacy of psychological therapy in schizophrenia: conclusions from meta-analyses. Schizophr. Bull. 32(Suppl. 1), S64-S80. doi: 10.1093/schbul/sbl030

Poltavski, D. V., and Petros, T. (2006). Effects of transdermal nicotine on attention in adult non-smokers with and without attentional deficits. Physiol. Behav. 87, 614-624. doi: 10.1016/j.physbeh.2005.12.011

Potter, A., Corwin, J., Lang, J., Piasecki, M., Lenox, R., and Newhouse, P. A. (1999). Acute effects of the selective cholinergic channel activator (nicotinic agonist) ABT-418 in Alzheimer's disease. Psychopharmacology (Berl.) 142, 334-342. doi: 10.1007/s00213005 0897

Przybyla, J. A., Cueva, J. P., Chemel, B. R., Hsu, K. J., Riese, D. J. 2nd., McCorvy, J. D., et al. (2009). Comparison of the enantiomers of (+/-)-doxanthrine, a high efficacy full dopamine $\mathrm{D}(1)$ receptor agonist, and a reversal of enantioselectivity at $\mathrm{D}(1)$ versus alpha(2C) adrenergic receptors. Eur. Neuropsychopharmacol. 19, 138-146. doi: 10.1016/j.euroneuro. 2008.10.002

Qu, W. M., Huang, Z. L., Xu, X. H., Matsumoto, N., and Urade, Y. (2008). Dopaminergic D1 and D2 receptors are essential for the arousal effect of modafinil. J. Neurosci. 28, 8462-8469. doi: 10.1523/JNEUROSCI.1819-08.2008

Ragland, J. D., Cools, R., Frank, M., Pizzagalli, D. A., Preston, A., Ranganath, C., et al. (2009). CNTRICS final task selection: long-term memory. Schizophr. Bull. 35, 197-212. doi: 10.1093/schbul/ sbn 134

Rezvani, A. H., Kholdebarin, E., Brucato, F. H., Callahan, P. M., Lowe, D. A., and Levin, E. D. (2009). Effect of R3487/MEM3454, a novel nicotinic alpha7 receptor partial agonist and 5-HT3 antagonist on sustained attention in rats. Prog. Neuropsychopharmacol. 
Biol. Psychiatry 33, 269-275. doi: 10.1016/j.pnpbp.2008.11.018

Roder, V., Mueller, D. R., Mueser, K. T., and Brenner, H. D. (2006). Integrated psychological therapy (IPT) for schizophrenia: is it effective? Schizophr. Bull. 32(Suppl. 1), S81-S93. doi: 10.1093/schbul/sbl021

Rushforth, S. L., Allison, C., Wonnacott, S., and Shoaib, M. (2010). Subtype-selective nicotinic agonists enhance olfactory working memory in normal rats: a novel use of the odour span task. Neurosci. Lett. 471, 114-118. doi: 10.1016/j.neulet.2010.01.022

Schultz, W. (2002). Getting formal with dopamine and reward. Neuron 36, 241-263. doi: 10.1016/S08966273(02)00967-4

Scoriels, L., Jones, P. B., and Sahakian, B. J. (2013). Modafinil effects on cognition and emotion in schizophrenia and its neurochemical modulation in the brain. Neuropharmacology 64, 168-184. doi: $\quad 10.1016 /$ j.neuropharm.2012. 07.011

Sheinin, A., Shavit, S., and Benveniste, M. (2001). Subunit specificity and mechanism of action of NMDA partial agonist Dcycloserine. Neuropharmacology 41, 151-158. doi: 10.1016/S00283908(01)00073-9

Silverstein, S. M., Spaulding, W. D., Menditto, A. A., Savitz, A., Liberman, R. P., Berten, S., et al. (2009). Attention shaping: a reward-based learning method to enhance skills training outcomes in schizophrenia. Schizophr. Bull. 35, 222-232. doi: $10.1093 / \mathrm{schbul} / \mathrm{sbm} 150$

Stefansson, H., Sarginson, J., Kong, A., Yates, P., Steinthorsdottir, V., Gudfinnsson, E., et al. (2003). Association of neuregulin 1 with schizophrenia confirmed in a Scottish population. Am. J. Hum. Genet. 72, 83-87. doi: 10.1086/345442

Stefansson, H., Sigurdsson, E., Steinthorsdottir, V., Bjornsdottir, S., Sigmundsson, T., Ghosh, S., et al. (2002). Neuregulin 1 and susceptibility to schizophrenia. Am. J. Hum. Genet. 71, 877-892. doi: 10.1086/342734

Strauss, G. P., Frank, M. J., Waltz, J. A., Kasanova, Z., Herbener, E. S., and Gold, J. M. (2011). Deficits in positive reinforcement learning and uncertainty-driven exploration are associated with distinct aspects of negative symptoms in schizophrenia. Biol. Psychiatry 69, 424-431. doi: 10.1016/j.biopsych.2010.10.015
Surmeier, D. J., Plotkin, J., and Shen, W. (2009). Dopamine and synaptic plasticity in dorsal striatal circuits controlling action selection. Curr. Opin. Neurobiol. 19, 621-628. doi: 10.1016/j.conb.2009.10.003

Swerdlow, N. R. (2011). Are we studying and treating schizophrenia correctly? Schizophr. Res. 130, 1-10. doi: 10.1016/j.schres.2011.05.004

Tamminga, C. A. (2006). The neurobiology of cognition in schizophrenia. J. Clin. Psychiatry 67(Suppl. 9), 9-13. discussion: 36-42. doi: 10.4088/JCP.0906e11

Taylor, G. T., Bassi, C. J., and Weiss, J. (2005). Limits of learning enhancements with nicotine in old male rats. Acta Neurobiol. Exp. (Wars.) 65, 125-136.

Thomsen, M. S., Hay-Schmidt, A., Hansen, H. H., and Mikkelsen, J. D. (2010). Distinct neural pathways mediate alpha7 nicotinic acetylcholine receptordependent activation of the forebrain. Cereb. Cortex 20, 2092-2102. doi: 10.1093/cercor/bhp283

Titone, D., Ditman, T., Holzman, P. S., Eichenbaum, H., and Levy, D. L. (2004). Transitive inference in schizophrenia: impairments in relational memory organization. Schizophr. Res. 68, 235-247. doi: 10.1016/S09209964(03)00152-X

Tobler, P. N., Fiorillo, C. D., and Schultz, W. (2005). Adaptive coding of reward value by dopamine neurons. Science 307, 1642-1645. doi: 10.1126/science. 1105370

Twamley, E. W., Jeste, D. V., and Bellack, A. S. (2003). A review of cognitive training in schizophrenia. Schizophr. Bull. 29, 359-382. doi: 10.1093/oxfordjournals.schbul.a007011

Twamley, E. W., Vella, L., Burton, C. Z., Heaton, R. K., and Jeste, D. V. (2012). Compensatory Cognitive Training for psychosis: effects in a randomized controlled trial. J. Clin. Psychiatry 73, 1212-1219. doi: 10.4088/JCP $12 \mathrm{~m} 07686$

Vinogradov, S., Fisher, M., Holland, C., Shelly, W., Wolkowitz, O., and Mellon, S. H. (2009a). Is serum brain-derived neurotrophic factor a biomarker for cognitive enhancement in schizophrenia? Biol. Psychiatry 66, 549-553. doi: 10.1016/j.biopsych.2009.02.017

Vinogradov, S., Fisher, M., Warm, H., Holland, C., Kirshner, M. A., and Pollock, B. G. (2009b). The cognitive cost of anticholinergic burden: decreased response to cognitive training in schizophrenia. Am. J. Psychiatry 166, 1055-1062. doi: 10.1176/appi.ajp. 2009.09010017

Waltz, J. A., Frank, M. J., Robinson, B. M., and Gold, J. M. (2007) Selective reinforcement learning deficits in schizophrenia support predictions from computational models of striatal-cortical dysfunction. Biol. Psychiatry 62, 756-764. doi: 10.1016/j.biopsych. 2006.09.042

Waltz, J. A., Frank, M. J., Wiecki, T. V., and Gold, J. M. (2011). Altered probabilistic learning and response biases in schizophrenia: behavioral evidence and neurocomputational modeling. Neuropsychology 25, 86-97. doi: 10.1037/a0020882

Waltz, J. A., Knowlton, B. J., Hoyoak, K. J., Boone, K. B., Mishkin, F. S., De Menedezes Santos, M., et al. (1999). A system for relational reasoining in human prefrontal cortex. Psychol. Sci. 10, 119-125. doi: 10.1111/14679280.00118

Weiler, J. A., Bellebaum, C., Brune, M., Juckel, G., and Daum, I. (2009). Impairment of probabilistic reward-based learning in schizophrenia. Neuropsychology 23, 571-580. doi: 10.1037/a0016166

Weiner, D. M., Meltzer, H. Y., Veinbergs, I., Donohue, E. M., Spalding, T. A., Smith, T. T., et al. (2004). The role of M1 muscarinic receptor agonism of N-desmethylclozapine in the unique clinical effects of clozapine. Psychopharmacology (Berl.) 177, 207-216. doi: 10.1007/s00213-004-1940-5

Weiss, E. M., Bilder, R. M., and Fleischhacker, W. W. (2002). The effects of second-generation antipsychotics on cognitive functioning and psychosocial outcome in schizophrenia. Psychopharmacology (Berl.) 162, 11-17. doi: 10.1007/s00213-0021053-y

Wolf, M. E., Sun, X., Mangiavacchi, S., and Chao, S. Z. (2004) Psychomotor stimulants and neuronal plasticity. Neuropharmacology 47(Suppl. 1), 61-79. doi: 10.1016/j.neuropharm.2004.07.006

Wykes, T., Huddy, V., Cellard, C., McGurk, S. R., and Czobor, P. (2011). A meta-analysis of cognitive remediation for schizophrenia: methodology and effect sizes. Am. J. Psychiatry 168, 472-485. doi: 10.1176/appi.ajp.2010.10060855

Wykes, T., Steel, C., Everitt, B., and Tarrier, N. (2008). Cognitive behavior therapy for schizophrenia: effect sizes, clinical models, and methodological rigor. Schizophr. Bull. 34, 523-537. doi: 10.1093/schbul/sbm114

Young, J. W. (2009). Dopamine D1 and D2 receptor family contributions to modafinil-induced wakefulness. J. Neurosci. 29, 2663-2665. doi: 10.1523/JNEURO SCI.5843-08.2009

Young, J. W., Amitai, N., and Geyer, M. A. (2012a). "Behavioral animal models to assess pro-cognitive treatments for schizophrenia," in Hanbook of Experimental Pharmacology, eds M. A. Geyer and G. Gross (Heidelberg: Springer), 39-79.

Young, J. W., Jentsch, J. D., Bussey, T. J., Wallace, T. L., and Hutcheson, D. M. (2012b). Consideration of species differences in developing novel molecules as cognition enhancers. Neurosci. Biobehav. Rev. doi: 10.1016/j.neubiorev.2012. 10.002. [Epub ahead of print].

Young, J. W., Powell, S. B., and Geyer, M. A. (2012c). Mouse pharmacological models of cognitive disruption relevant to schizophrenia. Neuropharmacology 62, 1381-1390. doi: 10.1016/j.neuropharm.2011.06.013

Young, J. W., Crawford, N., Kelly, J. S., Kerr, L. E., Marston, H. M., Spratt, C., et al. (2007a). Impaired attention is central to the cognitive deficits observed in alpha 7 deficient mice. Eur. Neuropsychopharmacol. 17, 145-155. doi: 10.1016/j.euroneuro. 2006.03.008

Young, J. W., Kerr, L. E., Kelly, J. S., Marston, H. M., Spratt, C., Finlayson, K., et al. (2007b). The odour span task: a novel paradigm for assessing working memory in mice. Neuropharmacology 52, 634-645. doi: 10.1016/j.neuropharm.2006.09.006

Young, J. W., Finlayson, K., Spratt, C., Marston, H. M., Crawford, N. Kelly, J. S., et al. (2004). Nicotine improves sustained attention in mice: evidence for involvement of the alpha7 nicotinic acetylcholine receptor. Neuropsychopharmacology 29, 891-900. doi: 10.1038/sj.npp. 1300393

Young, J. W., and Geyer, M. A. (2010). Action of modafinil-increased motivation via the dopamine transporter inhibition and D1 receptors? Biol. Psychiatry 67, 784-787. doi: 10.1016/j.biopsych.2009.12.015

Young, J. W., Meves, J. M., and Geyer, M. A. (2013). Nicotinic agonistinduced improvement of vigilance in mice in the 5-choice continuous performance test. Behav. 
Brain Res. 240, 119-133. doi: 10.1016/j.bbr.2012.11.028

Young, J. W., Meves, J. M., Tarantino, I. S., Caldwell, S., and Geyer, M. A. (2011). Delayed procedural learning in alpha7-nicotinic acetylcholine receptor knockout mice. Genes Brain Behav. 10, 720-733. doi: 10.1111/j.1601183X.2011.00711.x

Young, J. W., Powell, S. B., Risbrough, V., Marston, H. M., and Geyer, M. A. (2009). Using the MATRICS to guide development of a preclinical cognitive test battery for research in schizophrenia. Pharmacol. Ther. 122, 150-202. doi: 10.1016/j. pharmthera.2009.02.004

Young, J. W., Zhou, X., and Geyer, M. A. (2010). Animal models of schizophrenia. Curr. Top. Behav. Neurosci. 4, 391-433. doi: 10.1007/ 7854_2010_62

Zhang, J., Chen, X., Yu, L., Zhen, X., and Zhang, A. (2008). Synthesis of 6-substituted 1-phenylbenzazepines and their dopamine $\mathrm{D}(1)$ receptor activities. Bioorg. Med. Chem. 16, 9425-9431. doi: 10.1016/ j.bmc.2008.09.049
Conflict of Interest Statement: The authors declare that the research was conducted in the absence of any commercial or financial relationships that could be construed as a potential conflict of interest.

Received: 04 April 2013; accepted: 23 May 2013; published online: 18 June 2013

Citation: Acheson DT, Twamley EW and Young JW (2013) Reward learning as a potential target for pharmacological augmentation of cognitive remediation for schizophrenia: a roadmap for preclinical development. Front. Neurosci. 7:103. doi: 10.3389/fnins.2013.00103

This article was submitted to Frontiers in Neuropharmacology, a specialty of Frontiers in Neuroscience.

Copyright (C) 2013 Acheson, Twamley and Young. This is an open-access article distributed under the terms of the Creative Commons Attribution License, which permits use, distribution and reproduction in other forums, provided the original authors and source are credited and subject to any copyright notices concerning any third-party graphics etc. 